\title{
LA CRÍTICA JURÍDICA EN AMÉRICA LATINA: ALGUNOS ELEMENTOS PARA SU DISCUSIÓN
}

Autor: Sergio Martin Tapia Argïello

Licenciado en Derecho por la Benemérita Universidad Autónoma de Puebla, Maestro en Sociología por el Instituto de Ciencias Sociales y Humanidades Alfonso Vélez Pliego, Maestro en Derecho por la Universidad Nacional Autónoma de México, Maestrante en Global Rule of Law and Constitutional Democracy por la Universitá degli Studi di Génova, Candidato a Doctor en Human Rights in Contemporary Societies por el Centro de Estudos Sociais de la Universidade de Coimbra. El presen-te trabajo se ha desarrollado parcialmente gracias al apoyo obtenido por la Beca PD/ BD/114073/2015 del Fondo Social Europeo a través del programa Human Potential Operating y la Fundación para la Ciencia y la Tecnología de Portugal. Correo electrónico:parin75@gmail.com https://orcid.org/0000-0001-9456-0620.

\author{
Legal Critique in Latin-America: some \\ elements for its discusion
}

Fecha de recepción: 10 de abril de 2018 Fecha de aceptación: 3 de julio de 2018

Resumen: El presente trabajo realiza un acercamiento al derecho desde la Crítica Jurídica Latinoamericana. Para hacerlo, se realiza inicialmente un análisis tanto de las relaciones de poder en la academia, como en la manera en que se relaciona esto con la construcción del objeto de su estudio. Posteriormente, se analizan algunas características del derecho moderno, para establecer la necesidad de observar su carácter histórico, relacional y jerárquico, así como su vinculación con el capitalismo.

Palabras clave: Crítica Jurídica; Marxismo y Derecho; Conoci-
miento y exclusión; Filosofía del derecho latinoamericana.

Abstract: This paper develops an approach to the Law by the author's interpretation of Latin American Critical Legal Thinking. It starts with an analysis of the power structures in academia and how it is reflected on the studies that are made by academics on them. After this, it analyzes some characteristics of the modern Law to establish the necessity of understand both its historical, relational and hierarchical nature and its close relation with capitalism.

Keywords: Critical Legal Thinking; Marxism and Law; Knowledge and exclusion; Latin American philosophy of Law. 


\section{Introducción}

$L$ a construcción de una forma específica de realizar cualquier análisis crítico del Derecho "en, de, para y desde" América Latina parece situarse en la ya antigua pugna entre el universalismo y el relativismo regional del conocimiento filosófico y teórico.' La crítica, suele decirse, es una categoría universal anclada bajo ciertos parámetros que le distinguen de otras formas de hacer y analizar los fenómenos a las que, para colocarse en la dicotomía clásica, podríamos llamar "tradicionales"2 y como tal, una crítica jurídica propiamente latinoamericana, no puede existir sino como la configuración de esos presupuestos generales al análisis de una realidad determinada (la que se desarrolla en nuestra región). La crítica entonces, como toda forma de filosofía, sería universal en su existencia (y sus directrices) aunque regional en su aplicación.

Esta forma de entender a la teoría crítica y las posibilidades de existencia de una Crítica Jurídica Latinoamericana no es, contrario a lo que podría pensarse en un primer momento, una característica exclusiva de las corrientes y los pensadores tradicionales, sino una forma bastante extendida incluso dentro de ciertas visiones que se reconocen a sí mismas como "críticas" y que, desde sus prácticas y sus propias construcciones, asumen una postura transformativa radical y emancipadora de la realidad, aunque repitiendo al hacerlo, muchos de los principios epistémicos y éticos en que la existencia concreta de las formas de dominación existentes se sostienen y alimentan. ${ }^{3}$

De esta forma, no son pocas las voces que asumen la universalidad de ciertos presupuestos, no sólo epistemológicos sino principalmente ideológicos del conocimiento, así como la existencia de parámetros exclusivos (y excluyentes) de identidad del fenómeno conocido como "Derecho". ${ }^{4}$ A través de este doble proceso, se genera una legitimación de formas y saberes particulares que se presentan como los únicos que pueden ser nombrados como tales, ${ }^{5}$ al tiempo que se establece una universalidad total e inmutable de dichos fenómenos. ${ }^{6}$

En este sentido, el presente trabajo pretende mostrar algunos elementos para problematizar estas ideas desde la visión de la Crítica Jurídica Latinoamericana. En un primer momento, se hablará sobre las posibilidades de existencia de una forma particular de creación de conocimiento, así como las relaciones de poder existentes en esos procesos y que permiten, claramente, asumir la idea de que sólo ciertas visiones (que tienden, como es fácil adivinar, a ser formas occidentales, blancas, masculinas y claramente coloniales) pueden hablar desde la universalidad, mientras que otras son relegadas como parciales, locales e incompletas. Posteriormente, se establecerán algunos elementos para comprender una visión particular sobre la Crítica Jurídica Latinoamericana y problematizar la idea excluyente y universalizante del derecho como sistema normativo. ${ }^{7}$

\footnotetext{
1- Como uno de los más interesantes momentos de esta discusión, puede citarse el debate sobre la originalidad de la filosofía en América Latina que se dio con especial fuerza, durante los sesenta y setenta en la región. Cfr. Salazar Bondy, Augusto, ¿Existe una filosofía de Nuestra América?, México, Siglo XXI, 2008 y Zea, Leopoldo, La filosofía americana como filosofía sin más, México, Siglo XXI, 2011.

2- Horkheimmer, Max, Teoría tradicional y teoría crítica, Teoría crítica, Buenos Aires, Amorrortu, 2008.

3- Cfr. Sousa Santos, Boaventura, Crítica de la razón indolente. Contra el desperdicio de la experiencia, Bilbao, Descleé de Brower, 2012.

4- Esa es, por ejemplo, la idea desarrollada por Kelsen, Hans, Teoría pura del derecho, México, Porrúa, 2008.

5- Foucault, Michel, Genealogía del racismo, Buenos Aires, Caronte, 1996.

6- Cfr. Tamayo y Salmorán, Rolando, Introducción analítica al estudio del derecho, México, 2008, p. 11

7- Algunos de los argumentos desarrollados en el presente trabajo han sido presentados anteriormente en el Primer Congreso de
} 


\section{Sobre la articulación del conocimiento universal}

Dentro de las dinámicas desarrolladas en el trabajo académico, existe de manera constante un intento por superar lo que se considera, son los principales problemas de nuestra región en materia de filosofía y teoría del derecho: la doble fragmentación que tanto el localismo como la dependencia generan.

Tanto el derecho como el estado ${ }^{8}$ se encuentran aún anclados (aunque cada día de forma más problemática) al concepto de soberanía nacional, lo que limita, en muchas ocasiones, a quienes les estudian. No se trata sólo de la pugna entre el universalismo ${ }^{9}$ y el provincialismo ${ }^{10}$ de la teoría del derecho, sino que, incluso aquellos que se decantan por la primera de estas opciones y buscan generar un marco común de significado que permita trascender lo eminentemente nacional, se encuentran limitados por cuestiones fácticas concretas de la práctica jurídica, como la existencia de conocimientos nacionales específicos (ejemplos, casos, legislaciones, costumbres), posibilidades académicas reales (redes, capacidad de distribución e impacto, diálogos potenciales) así como por sus condiciones epistemológicas concretas (aspectos culturales e históricos como el lenguaje o las creencias hegemónicas de una nación).

\subsection{Periferia, exclusión y conocimiento}

De esta forma, resulta claro que a pesar de sus intenciones, la superación del localismo no está en manos de cualquiera que intente realizar un acercamiento teórico del derecho. Este problema, que involucra la desigual posesión de capitales simbólicos, económicos y culturales de los individuos, ${ }^{11}$ no puede ser sin embargo, reducido a características solamente personales, pues todo proceso de desigualdad contiene necesariamente, una dimensión estructural que la permite, alimenta, fortalece e invisibiliza.

En este sentido, el que existan ciertos actores que "tienen la capacidad" de universalizar sus propias prácticas dentro de la academia no implica un conocimiento mayor, mejor, más adecuado o amplio, sobre el fenómeno jurídico, sino que muestra que existe quienes tienen la posibilidad de hacer ver como universales sus propias y particulares visiones del mundo, categorías y prácticas cotidianas. Un ejemplo claro de esto es que la historia "universal" y la historia nacional se vuelven una y la misma en ciertos contextos occidentales, europeos, blancos y masculinos mientras que otras historias deben asumirse a si mismas como "locales" o parciales/incompletas. Después de

Filosofía del Derecho para el mundo latino.

8- En el presente trabajo se utilizará de forma general el concepto "estado" como sustantivo común. Esto no es un error, sino una postura política específica que atribuye un cierto sentido a esta manera de expresarse sobre él y que pretende hacer visibles los procesos de fetichización que le rodean. Cfr. Correas, Oscar, "La teoría general del derecho frente a los procesos de integración" en Witker, Jorge (coord.), El tratado de libre comercio de América del Norte, Tomo II, México, Universidad Nacional Autónoma de México, 1993, p. 30.

9- Pretensión que podemos encontrar en las más diversas corrientes de la filosofía jurídica. Cfr. e.g. Kelsen, Hans, Teoría pura del derecho, México, Porrúa, 2008; Stucka, P. I., La función revolucionaria del derecho y el estado, Barcelona, Península, 1969.

10- Cfr. Dworkin, Ronald, El imperio de la justicia, De la teoría general del derecho, de las decisiones e interpretaciones de los jueces y de la integridad política y legal como clave de la teoría y práctica, Barcelona, Gedisa, 1992.

11- Bourdieu, Pierre y Jean Claude Passeron, Los herederos, México, Siglo XXI, 1998, c. 1: La elección de los elegidos. 
todo, lo universalizable será aquello que es hecho por quienes tienen el "poder de nombrar"12 lo que es universal. Ante ello, el mundo latino debe recordar que:

"(N)uestras grandes teorías de las ciencias sociales fueron producidas en tres o cuatro países del Norte. Entonces, nuestro primer problema para la gente que vive en el Sur es que las teorías están fuera de lugar: no se adecuan realmente a nuestras realidades sociales. Siempre ha sido necesario para nosotros indagar una manera en que la teoría se adecúe a nuestra realidad. Pero hoy el problema es todavía mayor, porque nuestras sociedades están viviendo en un marco de globalización y vemos más claramente la debilidad de las teorías sociales con las cuales nosotros podemos trabajar". ${ }^{13}$

Así, la dependencia epistémica del sur global genera las condiciones ideales para la invisibilización de saberes y prácticas que no cumplen con las características que se asume, debe contener los conocimientos técnicos y científicos. De esta forma, tan sólo algunas prácticas jurídicas son presentadas como verdadero derecho, relegando al resto a categorías inferiores y por lo tanto supeditadas; al mismo tiempo, sólo algunos enfoques son asumidos como verdaderamente científicos y por lo tanto, válidos para el estudio de ese único derecho verdadero. Finalmente, sólo a estos se les considera capaces de ser universalizables, ${ }^{14}$ generando así una exclusión tautológica que se legitima a través de criterios demostrados (por si mismos) como "neutros". ${ }^{15}$

Muchas tradiciones epistémicas del sur han sido simplemente excluidas o supeditadas como locales e incompletas; tal es el caso de las formas, prácticas y saberes normativos de los pueblos y comunidades indígenas, mismos que se asumen, tienen un lugar propio y particularizado de análisis que de alguna manera se encuentra ajeno a la universalidad de la "verdadera" filosofía del derecho o bien de las reflexiones filosóficas sobre el "verdadero" derecho. Así, el estudio de esta cuestión se observa como el estudio de particularidades, mientras que otras particularidades son observadas como reflejo de lo universal.

Podemos, a través de estas reflexiones observar una línea abisal ${ }^{16}$ que cruza los pensamientos teóricos sobre el derecho: una visión dominante, que en mi trabajo he identificado con las "teorías tradicionales", una serie de visiones periféricas, que bajo los parámetros de saber establecidos a través de la visión dominante, generan conocimientos que son entendidos como válidos pero relegados a la periferia (como aquellos que desarrollan los académicos sobre los sistemas normativos no occidentales) y una serie de conocimientos invisibilizados que son totalmente excluidos (en este caso, el de los mismos pueblos y comunidades indígenas, a los que se niega la posibilidad de desarrollar una propia voz sobre el tema).

Desde mi perspectiva, una filosofía adecuada del mundo latino debe partir de una ecología

12- Bourdieu, Pierre, La fuerza del derecho. Elementos para una sociología del campo jurídico", Poder, derecho y clases sociales, Bilbao, Desclée de Brouwer, 2000, p. 202.

13- Santos, Boaventura de Sousa, "La sociología de las ausencias y la sociología de las emergencias: para una ecología de saberes", Renovar la teoría crítica y reinventar la emancipación social (encuentros en Buenos Aires), Buenos Aires, Agosto 2006, p. 15.

14- Santos, Boaventura de Sousa, Crítica a la razón indolente, Bilbao, Descleé de Brouwer, 2000.

15- Foucault, Michel, Genealogía del racismo, La Plata, Caronte, 1996, p. 20.

16- Santos, Boaventura de Sousa, "Beyond abyssal thinking. From Global Lines to Ecology of Knowledges", desde:http://www.boaventuradesousasantos.pt/media/pdfs/Beyond_Abyssal_Thinking_Review_2007.PDF, consultado el 23 de abril de 2016. 
de saberes ${ }^{17}$ que permita la inclusión tanto de saberes periféricos, como especialmente, de conocimiento invisibilizado que es tradicionalmente entendido como objeto de estudio secundario (de tipo antropológico, por ejemplo) y no como resultado de la reflexión de seres humanos con saberes y formas específicas y valiosas.

\section{La Crítica Jurídica Latinoamericana}

Estas ideas iniciales sirven para presentar una forma periférica de teorizar el fenómeno jurídico de las sociedades capitalistas contemporáneas: la Crítica Jurídica Latinoamericana (CJL), una postura que contrario a lo que en muchas ocasiones se piensa, ${ }^{18}$ no surge como una imitación o derivado de los intentos europeos y (norte) americanos de pensar el derecho desde una postura crítica, como los Critical Legal Studies ${ }^{19}$ o la Critique de droit, ${ }^{20}$ sino que tiene su propia genealogía, que crece y se desarrolla no bajo la sombra sino al lado de quienes en ese lado de la línea son un referente. ${ }^{21}$

Esta aclaración sirve para establecer distintos deslindes; por principio, respecto a una aproximación profundamente eurocéntrica de desarrollar el pensamiento crítico de nuestras sociedades, ${ }^{22}$ mismo que considero, se encuentra en crisis debido a la imposibilidad real de explicar una sociedad plural y dinámica con conceptos clausurados operacionalmente y anclados en visiones etnocéntricas e idealistas. De la misma forma, el trabajo de la CJL se ha desarrollado no bajo la premisa de la creación de abstractos universales que encasillan a la realidad, sino en la reflexión teórica sobre las acciones prácticas que desarrollan sus miembros, es decir, se trata de una corriente que entiende la importancia teórica de la práctica social y la dimensión práctica del "hacer teoría". ${ }^{23}$ Junto con esto, me permite hacer visible una cuestión que quienes desarrollamos pensamiento filosófico desde el sur global, enfrentamos constantemente: la idea de que el sur se encuentra imposibilitado para generar sus propios procesos de conocimiento.

Una característica común de lo que nosotros, desde el sur de América Latina hacemos, es una profunda oposición a aquellas visiones unívocas, ${ }^{24}$ que asumen la existencia de una sola realidad,

17- Santos, Boaventura de Sousa, "La sociología de las ausencias y la sociología de las emergencias: para una ecología de saberes”, óp. cit.

18- Wolkmer, Antonio Carlos, Introducción al pensamiento jurídico crítico, Bogotá, Instituto Latinoamericano de Servicios Legales Alternativos, 2003, Colección En clave de sur.

19- Estudios críticos legales. Corriente que surgió en los setentas en las Universidades americanas como una división de Law and Society (Derecho y Sociedad). Se ha caracterizado por contar con una enorme variedad de corrientes entre sus miembros (postestructuralistas, gramscianos de corriente culturalista, teorías de género, así como en menor medida marxista y anarquista), lo que le ha permitido no sólo un enfoque multidisciplinario, sino además triunfar en su búsqueda de no convertirse en una "gran teoría" cerrada del derecho. Su máximo representante es Duncan Kennedy, actualmente profesor de la escuela de derecho de Harvard. Cfr. Pérez Lledó, Juan, El movimiento de los critical legal studies, Madrid, Tecnos, 1996.

20- Crítica del derecho. Grupo francés de estudios críticos sobre el derecho, con una formación marxista mucho más homogénea que el anterior, principalmente althuseriana. Comparte con los CLS la aversión de una teoría general del derecho excluyente. Cfr. Jeammaud, Antoine, Sur critique de droit, conferencia impartida en el evento "Franco-American Legal Influences, Then and Now" celebrado el 12 y 13 de junio de 2011 en la Harvard Law School.

21- Al respecto, cfr. Correas, Oscar, "Conferencia Inaugural” en VIII Conferencia Latinoamericana de Crítica Jurídica Jornada Argentina, Universidad Nacional de La Plata, La Plata, 29- 30 de agosto de 2013.

22- Santos, Boaventura de Sousa, Decolonizar el poder, reinventar el poder, Montevideo, Trilce, 2010, pp. 20-21

23- Cfr. Marx, Karl, “Tesis sobre Feuerbach”, desde: https://www.marxists.org/espanol/m-e/1840s/45- feuer.htm, consultado el 23 de abril de 2016.

24- Beuchot, Mauricio, Tratado de hermenéutica analógica, México, Universidad Nacional Autónoma de México, 2009. 
de un camino para aprehenderla y de una forma de expresarla. ${ }^{25}$ Por ello, es necesario indicar que no creo que exista una sola crítica jurídica, así como no creo que sea posible hablar de una sola verdad universal en ningún otro tema.

\subsection{Teorías tradicionales y teorías críticas}

Contrario a lo que podría parecer en una primera lectura, la afirmación contra el univocismo y el esencialismo que podría presentarse ante la idea de "La Crítica Jurídica" no significa la aceptación de un relativismo total sobre su contenido. Si bien considero que la definición no es una herramienta adecuada para llevar a cabo la presentación de mi postura, considero que existen algunos elementos que deben ser mencionados, con la finalidad de mostrar que no todo análisis de la realidad debe ser entendido como "crítico", a pesar de las múltiples posibles interpretaciones que este vocablo presenta. ${ }^{26}$

La división formulada en el presente trabajo entre teorías tradicionales y teorías crítica, sigue las líneas generales de lo establecido por Max Horkheimmer, ${ }^{27}$ gracias al cual entendemos como tradicionales a las posturas que asumen la naturalidad o simplemente no cuestionan la existencia de ciertos parámetros de discusión iniciales, es decir, que establecen un "coto vedado" incuestionable para lograr un proceso comunicativo. Por su parte, las teorías críticas parten de la idea de que la crítica debe ser implacable y contra todo lo existente, incluyendo por ello (quizá principalmente) a todo lo que parece no poder ser cuestionado. ${ }^{28}$

Como puede observarse, mi aproximación crítica parte de principios marxistas. ${ }^{29}$ Esto no significa ni que considere que la única crítica posible es la desarrollada por Marx, ni que el marxismo contenga de forma específica las mejores herramientas posibles para analizar cualquier tipo de realidad social de forma genérica. Significa, más bien, que mis propias características, historia y desarrollo personal, me han proporcionado una serie de herramientas teóricas, ${ }^{30}$ entre las cuales se encuentra el marxismo, por lo que hago uso de ellas bajo sus propias posibilidades y con una profunda vigilancia epistemológica ${ }^{31}$ de sus y mis limitaciones.

25- Santos, Boaventura de Sousa, Crítica de la razón indolente, óp. cit., especialmente c. 1: De la ciencia moderna al nuevo sentido común.

26- Cfr. Correas, Oscar, “Acerca de la crítica jurídica” en El otro derecho, número 5, marzo de 1990, ILSA, Bogotá D.C., Colombia, pp. 35- 51.

27- Horkheimer, Max, "Teoría tradicional y teoría critica" en Teoría crítica, Buenos Aires, Amorrortu, 2008. 23 Marx, Karl, "Cartas de Marx a Ruge (marzo y septiembre de 1843)", Escritos de Juventud sobre el Derecho, Textos 1837-1847, Rubén Jaramillo (trad., y ed.), Barcelona, Anthropos, 2008, p. 89.

28- Marx, Karl, "Cartas de Marx a Ruge (marzo y septiembre de 1843)", Escritos de Juventud sobre el Derecho, Textos 1837-1847, Rubén Jaramillo (trad., y ed.), Barcelona, Anthropos, 2008, p. 89.

29- Ante la pregunta de si un pensamiento formulado en Europa, por europeos y que se asume, piensa el mundo como Europa, puede generar una reflexión adecuada para nuestras realidades, recomiendo Santos, Boaventura de Sousa, "¿É possível decolonizar o marxismo? Capitalismo, colonialismo e patriarcado", Segunda aula magistral 2016, desde: https://www.youtube.com/watch?v=79rUpxLI_ $\mathrm{NI}$, consultado el 23 de abril de 2016.

30- Foucault, Michel, “Poderes y Estrategias”, Un diálogo sobre el poder y otras conversaciones, Madrid, Alianza, 2008 , p. 85.

31- Bourdieu, Pierre et al., El oficio de sociólogo, México, Siglo XXI, 2008. 


\subsection{Crítica positiva y crítica negativa}

La crítica jurídica es crítica en el sentido de negar las bases fundamentales en que se sustenta el derecho moderno. Por supuesto, no digo que toda crítica jurídica haga esto, sino que cuando yo me refiero a crítica jurídica, hago referencia a una postura no sólo metodológica sino epistemológica que cuestiona esas bases, comúnmente aceptadas, dentro del discurso que llamamos derecho moderno. A esta forma de entender a la crítica jurídica, podemos llamarla "crítica negativa", mientras que aquella que se desarrolla dentro de los límites que el mismo derecho asume tener, es decir que se lleva a cabo sin cuestionar los fundamentos del derecho moderno la llamaremos una "crítica positiva". ${ }^{32}$

No intento a través del presente trabajo, indicar que existe una preeminencia de la crítica negativa sobre la positiva o bien que la crítica positiva sea "menos crítica" del derecho. Se trata, en muchas ocasiones, de momentos distintos y mutuamente necesarios. Existen ciertas visiones que parecen en un principio críticas positivas en el sentido de que "critican" al derecho sin cuestionar sus postulados centrales y al hacerlo tiene la finalidad de perfeccionar aquellas contradicciones que resultan inherentes de la forma jurídica, entre los que se encuentra una forma específica de dominación. Esta forma de entender a la crítica muestra el problema de considerar cualquier tipo de análisis como "crítico", término que, en mi caso, limito a aquello que cuestiona, total o parcialmente esos parámetros.

Al lado de ella, sin embargo, existen otras formas críticas, que si bien no cuestionan de forma general los fundamentos del derecho si cuestionan al derecho tal y cómo se presenta en una sociedad determinada, y al hacerlo se valen de él para hacer de este mundo un lugar más justo. Esta visión, que podemos llamar transformativa, pocas veces se acompaña de una idea totalmente "positiva" (con doble sentido: en cuanto acepta la realidad como dada y en cuanto la encuentra como algo favorable) del derecho y sus postulados iniciales; en muchas ocasiones, se trata más bien de una separación estratégica entre lo que debemos hacer en este momento para una situación determinada y lo que pensamos sobre el derecho. Aun cuando no fuera así, por sus resultados, la visión transformativa resulta igualmente importante, si no es que en algunos momentos más, para nuestra vida cotidiana y para la lucha, que una visión crítica solamente negativa. ${ }^{33}$

El problema de la visión transformativa, es que para hacer lo que busca, debe allanarse, aunque sea temporalmente, a ciertos presupuestos comunes para logar una lucha adecuada, lo que puede generar algunos problemas. Uno de ellos, quizá el más peligroso, es que pueden existir consecuencias no previstas que te lleven de la simple legitimación momentánea, al fortalecimiento o incluso a la defensa de aquellas cuestiones a las que en el fondo, te opones. ${ }^{34}$ Por ello, una crítica positiva del derecho tiene necesidad de esa otra crítica, a la que yo hago referencia y que llamamos "crítica negativa", que sirva como ancla para la búsqueda de una transformación radical; de la misma forma esta crítica negativa tiene necesidad de la crítica positiva, al menos si no quiere convertirse en una abstracción inútil.

\subsection{La dialéctica entre crítica negativa y positiva.}

Así, las líneas generales de mi trabajo discurren entre ambas caras, artificialmente separadas, de la crítica jurídica. Iniciar el análisis de lo concreto, realizar un proceso de abstracción y retornar a lo concreto resulta necesario en ese esfuerzo. Si esta forma de ver y entender el derecho

32- Correas, Oscar, "Acerca de la crítica jurídica” óp. cit.

33- Ejemplos claros de esta forma, son tanto el uso alternativo del derecho como el litigio estratégico.

34- Horkheimer, Max, Estado autoritario, trad. Bolívar Echeverría, México, Ítaca, 2006, p. 36. 
asume como necesario minar las bases aceptadas de antemano de aquello que es nombrado de esa manera derecho, si pide que demos la espalda a la seguridad ontológica que nos proporciona el terreno conocido, no lo hace de forma gratuita.

El derecho, tal y como ahora se presenta en las visiones hegemónicas, es un campo de lucha. Sin embargo, las reglas y especialmente el terreno son tan disímbolamente favorables a un grupo que por momentos parece ser una herramienta y se convierte entonces en una forma de dominación. Contra esto, la crítica jurídica cuestiona, rompe pero especialmente, y ahí yace su potencialidad, devela aquello que el derecho y especialmente quienes se encuentran en una relación de superioridad en ese campo, no quieren que se vea.

Quizá una de las formas más efectivas para mostrar los elementos más importantes de esta aproximación, sea desarrollar, en esta segunda parte de la ponencia, las características que desde mi perspectiva, asumen las relaciones jurídicas en la modernidad.

\section{El derecho en la visión de la CJL}

Existen distintos problemas para lograr una definición correcta de "lo jurídico", como existe también para definir crítica. Contrario a lo que podría parecer a primera vista, el derecho no es un fenómeno que pueda ser fácilmente conceptualizado. Esto se debe en parte 1) a que se trata de un término polisémico, que hace referencia a diferentes actividades que no parecen más que remotamente relacionadas entre sí, ${ }^{35}$ en parte 2 ) a que es un término ambiguo, pues nombra al mismo tiempo tanto a distintas actividades como a niveles diferentes de cada una de ellas y en parte 3 ) porque se trata de un término abierto. ${ }^{36}$

Cada una de estos problemas tiene una importancia capital para la crítica jurídica que realizo, sobre todo porque si bien los dos primeros son comúnmente aceptados por ciertas visiones tradicionales (aunque quizá no en el sentido de la crítica jurídica), el tercero no sólo es ocultado sino abiertamente negado por la gran mayoría de ellas. Esto se debe sin duda alguna, a que al mirar al derecho de esta manera, existe la posibilidad nada remota de observar tanto el papel contradictorio de su existencia, como la reconfiguración de los elementos que parecen generalmente fijos y como tales, convenientemente inamovibles.

\subsection{El derecho como concepto abierto}

Por ello, considerar que cuando hablamos de derecho hacemos referencia a un término abierto, significa aceptar que la fijeza monolítica con la que el derecho moderno se presenta no es más que un mito. ${ }^{37}$ Puede ser considerado un mito genial, toda vez que ha logrado mantenerse oculto como tal durante al menos, doscientos años, pero no dejará de ser un mito. El derecho no es un fenómeno acabado, algo que es, sino que se trata de una categoría que constantemente está

\footnotetext{
35- Tamayo y Salmorán, Rolando, Razonamiento y argumentación jurídica. El paradigma de la racionalidad y la ciencia del derecho, México, Universidad Nacional Autónoma de México, Instituto de Investigaciones Jurídicas, 2003, pp. 71- 73.

36- Para identificar la postura de entender a los procesos sociales como abiertos, Cfr. Bonefeld, Werner et al., Marxismo abierto, una visión europea y latinoamericana, Vol. II, Buenos Aires, Herramienta, 2007.

37- Uno de muchos otros mitos que rodean el surgimiento y la existencia misma del derecho. Al respecto, cfr. Fitzpatrick, Peter, La mitología del derecho moderno, México, Siglo XXI, 1998.
} 
siendo. Esto significa por supuesto que su transformación no se limita a los "órganos del estado" autorizados para cambiar el derecho y volverlo después de su actuación, nuevamente una unidad cerrada, acabada, sino que a través de diversos mecanismos, el derecho se reconfigura todo el tiempo. ${ }^{38}$ Cuando cada uno de nosotros habla del derecho, lo modifica. Por supuesto, existen modificaciones que tienen más impacto, pero eso no significa, como pretenden las teorías tradicionales que esas ocasiones sean las únicas que importen.

El que el derecho es un fenómeno social abierto es muy claro si observamos las diferencias que un mismo ordenamiento puede tener en dos momentos distintos, incluso sin la intervención de los órganos legítimamente facultados para ello. No sólo a través de las reformas o de criterios interpretativos específicos se transforman las normas, sino que muchas otras interpretaciones socialmente no reconocidas cambian tanto la aplicación como los alcances de ella.

Tradicionalmente se recurre para explicar esto a una idea divisionista de la sociedad. Se asume la existencia de un objeto "a" llamado sociedad que existe con independencia de otro objeto " $b$ " llamado derecho. Las transformaciones en "a" no cambian a "b" puesto que se trata de objetos independientes entre ellos, pero si cambian los efectos de " $b$ " en "a" e incluso, generan condiciones para que por sus propios procesos internos, "b" se reconfigure. ${ }^{39}$

Quizá la razón por la que esta visión se ha logrado mantener durante todo este tiempo, es su amplio poder profético. La imagen del derecho como una cosa, como un término cerrado y acabado nos indica que bajo cierta condición " $X$ " el derecho se comportará de una manera determinada " $Y$ ". Cuando " $Y$ " sucede, y esto pasa muchas veces, no podemos entonces dejar de pensar que esa forma de entender el derecho es la correcta. Después de todo, ha logrado prever las acciones del derecho y eso sólo puede hacerse si se conocen las características de lo que el derecho es.

Cuando nos movemos en este sentido, nos olvidamos, en ocasiones se trata de esos convenientes olvidos voluntarios de la ideología, de que el derecho es una relación social ${ }^{40}$ y no sólo el reflejo de ella; que como tal, el derecho es construido (muchas veces de forma inconsciente) por personas que han sido educadas y han aprendido a lo largo de su vida que en la situación " $X$ ", el derecho actuará de la forma "Y" y que por lo tanto han hecho " $Y$ ". Es decir, olvidamos que el poder que el derecho tiene, es el de ser una profecía capaz de autocumplirse. ${ }^{41}$

\subsection{El derecho como relación social}

Como se ha mencionado ya con anterioridad, la crítica jurídica busca demostrar que el derecho es una relación social. ${ }^{42}$ Más importante aún, que se trata de una forma específica de relación social, es decir, que se trata de una forma que asumen las relaciones sociales dentro de las socie-

38- $Y$ con esto me refiero al nivel del derecho positivo, cosa que muchas corrientes aceptan, pero también al estudio científico del derecho, que se considera generalmente distinto en este aspecto. En este momento, podemos entonces observar uno de los múltiples problemas al referirnos al derecho y a la relación entre éste y el conocimiento.

39- Esta visión puede ser encontrada en posturas como el estructuralismo (que considera la idea del "reflejo"), el marxismo (superestructura) y la teoría de sistemas (sistemas y subsistemas).

40- En este sentido, Pashukanis, E., Teoría general del derecho y el marxismo, México, Grijalbo, 1976.

41- Al respecto, cabe recordar que como indica Pierre Bourdieu, en el derecho existen ciertas reglas de auto control interno, que al escapar del ámbito personal de decisión sirven como reforzamiento de este proceso. Bourdieu, Pierre, La fuerza del Derecho, Bogotá, Siglo del hombre editores, Facultad de Derecho Universidad de los Andes, Ediciones UniAndes, Instituto Pensar, 2000, pp. 168 y ss.

42- Correas, Oscar, “El derecho como forma social” en Ideología jurídica, Puebla, Universidad Autónoma de Puebla, 1983. 
dades contemporáneas, con características específicas y concretas. ${ }^{43}$

Para comprender e identificar apropiadamente estas características, debemos recordar que el derecho es un fenómeno histórico, en un doble sentido; el derecho está inmerso en la historia, lo que significa que se encuentra vinculado con otras formas específicas de relaciones sociales, que no se encuentra acabado y se reconfigura constantemente y al mismo tiempo, el derecho tiene una historia, que como toda historia, fragmentaria, con rupturas, desencuentros y reencuentros, nos ayuda a comprender algunas de las circunstancias actuales y vislumbrar su contingencia.

\subsection{El derecho como elemento histórico}

Existen, cuando hablamos sobre la historia del derecho, dos posturas perfectamente identificables. La primera es aquella que establece la existencia en toda sociedad, de un sistema que pueda ser considerado como derecho. Esta visión, sustentada en el peso de la tradición desde el aforismo latino "Ubi societas ibi ius, ubi ius ibi societas" 44 es la que lleva a afirmar que "(I)a historia proporciona contundente evidencia sobre la persistencia de la palabra 'derecho'. Hace miles de años que la comunicación humana ha requerido tal expresión". ${ }^{45}$

Existe otra postura que establece la peculiaridad del sistema que llamamos derecho, identificándolo de forma total con la modernidad. ${ }^{46}$ De acuerdo a esta visión, las características del derecho son una conjunción de particularidades que solo son posibles bajo un horizonte discursivo, económico, político y social específico: el de la modernidad occidental.

A pesar de lo que parece a primera vista, no es necesario considerar ambas posturas como opuestas:

Evidentemente, toda sociedad, por más elemental que sea, no puede dejar de darse un conjunto de reglas, que podemos también llamar 'derecho'(...) De este modo, sin embargo, nos servimos sólo de una especie de asimilación analógica, que toda vez que nos parece distinguir en aquellas lejanas realidades aspectos que se dejan asociar a la idea para nosotros de otro modo familiar. ${ }^{47}$

\footnotetext{
43- Esta visión ha sido combatida en múltiples ocasiones. Así, para Kelsen existen diversos problemas para entender al derecho como una relación social y no como un sistema de normas; entre ellos, se encuentran la dificultad para identificar la especificidad de dichas relaciones sociales respecto a otras; una profunda confusión entre el mundo de los hechos y el derecho; la imposibilidad de demostrar la existencia de una realidad social- comunitaria sin derecho que se deriva teóricamente de ella y finalmente, la existencia de saltos argumentativos que cruzan de forma indiscriminada la división entre derecho positivo y ciencia del derecho. Kelsen, Hans, Teoría comunista del derecho y el estado, Buenos Aires, Emecé, 1957, cc. III: La teoría del derecho de Stuchka y V: La teoría del derecho de Pashukanis. Algunos de estos elementos serán explicados en las siguientes páginas, pero quisiera establecer desde aquí, que una visión normativista del derecho, es al mismo tiempo, una visión sobre el derecho como una relación social, comunicacional y comunitaria. La visión de Stuchka y Pashukanis parte precisamente del ocultamiento de esta cuestión en la teoría pura para considerarle "ideológica" (en sentido "negativo"), cosa que desde mi perspectiva, Kelsen simplemente deja de lado.
}

44- Traducido comúnmente como "Donde hay sociedad, hay derecho, donde hay derecho, hay sociedad". Cfr. Pina Vara, Rafael de, "Aforismos y frases latinas" en Diccionario de derecho, México, Porrúa, 1997.

45- Tamayo y Salmorán, Rolando, Introducción analítica al estudio del derecho, México, Themis, 2011, p. 5.

46- Por ejemplo, Miaille, Michel, "La especificidad de la forma jurídica burguesa" en La crítica jurídica en Francia, Puebla, Universidad Autónoma de Puebla, 1986.

47- Schiavone, Aldo, lus. La invención del derecho en occidente, Buenos Aires, Adriana Hidalgo editora, 2009, p. 15. 
Así, el uso que se da en la primera postura al término derecho, hace referencia a un equivalente funcional, en otro tiempo y otras circunstancias, de lo que nosotros en la actualidad entendemos como "derecho". ${ }^{48}$ Derivado de ello, algunas visiones modernas del derecho, especialmente aquellas que pueden ser consideradas como tradicionales- apologistas, pretenden encontrar a través de una homologación del discurso, una verticalidad histórica innegable, una presencia sempiterna del derecho y sus características como fundamento de su propia existencia. Para ello, recurren tanto a trucos lingüísticos como a traducciones homogeneizantes que hacen creer en la eternidad del derecho.

Por el contrario, una visión crítica debe partir de la diferenciación del fenómeno jurídico "derecho" y al mismo tiempo, de la posibilidad de traducción que se encuentra en él, ${ }^{49}$ así como de la potencialidad política de utilizar el concepto ante realidades diferentes. ${ }^{50}$

\subsection{El derecho como sistema normativo}

Si el derecho no es entonces, como en algunas ocasiones se dice, eterno, podemos identificar que existen y han existido otras formas sociales similares a él. La función del derecho consiste en regular la vida social del ser humano, esfuerzo que comparte con a moral, la religión o los usos sociales, por poner los ejemplos más claros.

Para llevar a cabo este objetivo, el derecho se vale de un conjunto de normas, más específicamente, usa un conjunto de normas que se organizan como un sistema. ${ }^{51}$ El derecho, así como el resto de los elementos mencionados, son entonces sistemas normativos.

Resulta necesario, en este momento, establecer una diferencia que me parece fundamental en la lectura llevada por Kelsen. El derecho es un sistema normativo no sólo porque se trate de un conjunto de normas que funcionan de forma sistémica exclusivamente entre ellas, sino porque funcionan como un sistema con un conjunto de formas sociales que se presentan como separadas o incluso supeditadas a él. ${ }^{52}$

Esta ruptura no es casual. El derecho, al menos desde la postura apologista, pretende mostrarse como un conjunto de normas sistémico al interior y no como un sistema normativo social debido a que los límites de acción se ven profundamente limitados de esta manera; "es una característica de las relaciones de producción capitalistas" nos dice Holloway, "el no expresarse en ninguna manera simple como relaciones de dominación". Antes bien, estas formas sociales de dominación se presentan en nuestra vida cotidiana como "una serie de formas discretas (...) no como formas de dominación clasista, sino como cosas inconexas". ${ }^{53} \mathrm{Al}$ respecto, Marx nos indica que dentro del capitalismo,

\footnotetext{
48- Y por ello, algunos hablan entonces de "derecho moderno" para referirse a lo que nosotros llamamos simplemente derecho.

49- Santos, Boaventura de Sousa, "La sociología de las ausencias y la sociología de las emergencias: para una ecología de saberes", óp. cit.

50- Correas, Oscar, Derecho indígena mexicano, tomo 1, México, Coyoacán, 2011.

51- 46 Kelsen, Hans, Teoría general del derecho y del estado, México, Universidad Nacional Autónoma de México, 2010, p. 3: “El derecho es un orden de la conducta humana. Un 'orden' es un conjunto de normas... Es un conjunto de normas que tiene el tipo de unidad a que nos referimos cuando hablamos de un sistema."

52- Así, por ejemplo, el llamado 'aparato' de justicia (policías, ministerios públicos, jueces) que bajo la visión de Kelsen sólo son tales en cuanto existe una norma que les da sentido.

53- Holloway, John, "El estado y la lucha cotidiana" en Cuadernos políticos, número 24, México, Distrito Federal, editorial Era, abril-
} 
estas formas parecen perder a través de esto, la conexión interior, mostrándose cada vez más, como ajenas unas a las otras. ${ }^{54}$ Sólo entendido de esta forma, es que Kelsen puede comprender al derecho como un sistema normativo pero no como una relación social.

\subsection{El derecho como fenómeno racional}

El camino que siguió esta ruptura se encuentra estrechamente vinculado al surgimiento de una forma específica de racionalidad que es denominada "instrumental". ${ }^{55} \mathrm{Si}$ bien la forma actual de la misma es identificable a partir de los procesos de tecnificación de la producción y la consolidación del aparato burocrático moderno, debemos entender que se trata de un proceso largo y discontinuo, ${ }^{56}$ que tiene entre sus antecedentes, quizá contingentes, a la formación específica de la subjetividad que se desarrolla a través del individuo, la separación discursiva y especialización de los sistemas normativos y la difuminación estamental de clasificación social- comunitaria.

De esta manera, la forma jurídica se presenta como una racionalización de la justicia, es decir, una forma ordenada y jerarquizada, con criterios supra-personales de definición y constitución, que atiende a la necesidad de la sociedad como conjunto a través de criterios objetivos. Para lograr esto el derecho cuenta con una herramienta que no ha existido en otros sistemas normativos hegemónicos y que tiene una innegable cuna romana: la abstracción de la norma. Así:

“...la estructura diairética requería siempre, en toda aplicación, un presupuesto esencial: la conquista de un sólido nivel de abstracción respecto a los conocimientos encuadrados en ella.

(...)

Pero esta condición no se daba de hecho por descontada en el saber jurídico, antes del cambio drástico de Mucio. Aquí, todo el recorrido del trabajo de los pontífices en la jurisprudencia del siglo II a.C. mostraba el esfuerzo de un fatigoso y todavía inconcluso camino hacia construcciones capaces de sobrepasar el carácter rígidamente casuístico de la experiencia del ius. ${ }^{57}$

Weber identificaba en estas características el surgimiento de lo que él llamaba la "dominación jurídica-burocrática", es decir, una forma de legitimación del orden establecido a través del imperio de la razón, materializada en una serie lógica y racionalmente compuesta de normas organizacionales, que limitan las acciones de los órganos de poder así como de los individuos a la vez que divide y jerarquiza las competencias de los mismos. ${ }^{58}$

junio 1980. p. 17.

54- Marx, Carlos, El capital, crítica de la economía política, Tomo III, México, Fondo de Cultura Económica, 2008, p. 766.

55- La racionalidad instrumental es un tipo de acción social (es decir de forma de interacción) que se desarrolla de acuerdo a fines racionalmente definidos. Cfr. Weber, Max, Economía y sociedad, México, esbozo de sociología comprensiva, Fondo de Cultura Económica, 2008 y Horkheimer, Max, La racionalidad instrumental, Madrid, Trotta, 2006.

56- Como ha sido posible ver a lo largo del presente trabajo, existe en mi postura un rechazo tajante a la causalidad histórica. Para abundar en esta postura, cfr. Foucault, Michel, La arqueología del saber, México, Siglo XXI, 2007.

57- Schiavone, Aldo, lus, la invención del derecho en occidente, óp. cit., pp. 232-233.

58- Weber, Economía y sociedad, México, Fondo de Cultura Económica, 2008, pp.173-180. 
En el derecho, el proceso de racionalización significó diversas cosas. Por principio, debemos identificar que nuestro sistema jurídico tiene una diferencia fundamental respecto al resto de los sistemas normativos históricamente existentes, diferencia que además se presenta, ideológicamente como el resultado del desarrollo del ser humano, es decir, como si se tratara de la forma más acabada o perfecta. Si bien Pashukanis encuentra esta diferencia en la creación de un sujeto propietario y la pugna de este con otro igual, ${ }^{59}$ y Miaille la encuentra en la estatización y objetivación de dicha forma, ${ }^{60}$ lo que hace verdaderamente diferente a este sistema jurídico se trata precisamente en que se muestra como un sistema "racional", en donde la pugna entre iguales e incluso la existencia misma de esos iguales, son debidas a la racionalidad, es decir al resultado del esfuerzo humano para lograr la comprensión del mundo utilizando para ello su capacidad intelectual, y como tal, un esfuerzo cuyo resultado se presenta de forma organizada y metódica: una capacidad de previsión ${ }^{61}$ que solo puede ser resultado de un trabajo racional y sistemático.

Como en otros casos, Weber consideró que esta especificidad era algo exclusivamente occidental. Se trata por principio de una "sistematización científica de la teoría del derecho, las instituciones del derecho formal y una judicatura ejercida por funcionarios especializados en derecho"62 basada para ello en el derecho positivo, o mejor dicho en una forma específica de derecho positivo: la ley, ${ }^{63}$ que como conjunto normativo abstracto y codificado es uno de los elementos principales y constituyentes de la forma normativa que llamamos derecho. ${ }^{64}$

\subsection{Derecho y capitalismo}

Como otras formas de racionalización occidental, los procesos que se generaron en y a través del derecho moderno encuentran en el sistema de producción capitalista a un compañero ideal y en el espíritu moral que le guía al complemento ideal de su propio desarrollo. ${ }^{65}$ Por ello, el predominio de esta forma específica como fuente de legitimación del modo de producción capitalista no

59- Pashukanis, Teoría General del Derecho y el Marxismo, óp. cit., pp. 67- 68: "Con ello hemos anticipado hasta cierto punto la respuesta planteada al principio: ¿dónde hay que buscar esa relación social sui géneris cuyo reflejo inevitable es la forma jurídica? A continuación trataremos de probar en detalle que esa relación es la relación de los propietarios de mercancías entre sí"

60- Miaille, op. cit., p. 35.

61- Cfr. Poulantzas, Nicos, "La teoría marxista del estado", Hegemonía y dominación en el estado moderno", Buenos Aires, Siglo XXI, 1969, Cuadernos de pasado y Presente 48, p. 25: "El examen general de la especificidad jurídica- estatal de las sociedades occidentales actuales comenzará con el análisis del carácter particular que esos valores registren en nuestro tiempo. Un nuevo elemento se agrega, sin embargo, como factor de estructuración de esta especificidad actual: la necesidad de cálculo de previsión.". De acuerdo a Poulantzas, esta no se refiere solamente al proceso de racionalidad (entendida como sistematización) exigida y estudiada por Weber desde los romanos, sino que tiene además una diferencia cualitativa, puesto que en las sociedades actuales se requiere la posibilidad de calcular de antemano los efectos de nuestros actos. Como se verá a continuación, me parece que la teoría weberiana se refiere como racionalización no sólo a la sistematización sino también entre otras cosas, a la predictibilidad a la que se hace alusión desde el estructuralismo marxista.

62- Habermas, Jürgen, Teoría de la acción comunicativa, Tomo 1: Racionalización de la acción y racionalización social, Madrid, Taurus, 1999, pp. 213- 214.

63- Weber, Max, “Introducción”, Ensayos sobre sociología de la religión, tomo 1, Madrid, Taurus, 1987, p. 13.

64- Grossi, Paolo, “¿Justicia como ley o ley como justicia? Anotaciones de un historiador del derecho" en Mitología jurídica de la modernidad, Madrid, Trotta, 2003, pp. 21-22.

65- Cfr. Weber, Max, La ética protestante y el espíritu del capitalismo, México, Colofón, 2004. 
es fortuito ni espontáneo. La transformación entre un modelo de acumulación ${ }^{66}$ y de producción basado en el control de la tierra y uno que se basa en la explotación del hombre libre, ${ }^{67}$ se conjugó, en muchas ocasiones gracias al interés de quienes se involucraron en esas relaciones de poder y cooperación, con el resurgimiento y reinterpretación de ciertas instituciones y saberes del ius. ${ }^{68}$

En esa pugna por el poder y más importante aún por la facultad de indicar los límites del mismo, esta nueva forma se presenta primero como un terreno de lucha para después mostrarse como la forma última de la realidad misma. A través del proceso de centralización del poder administrativo, la codificación se presenta en el conflicto entre los pequeños señores feudales y un centro administrativo generalmente citadino manejado por la burguesía que poco a poco se hace del control por este proceso. ${ }^{69}$

Así, la máscara por medio de la cual lo jurídico se naturaliza, encuentra sus antecedentes en esa centralización y la consiguiente desaparición de los poderes locales durante la parte final de lo que tradicionalmente se nombra como feudalismo así como en el proceso de normalización ${ }^{70}$ de la sociedad a inicios del capitalismo temprano, es decir, el doble proceso por medio del cual las conductas se meten en una norma al mismo tiempo que por ese hecho (y solo por él) se vuelven normales. ${ }^{71}$

\section{A manera de conclusión}

Como he comentado al inicio del presente trabajo, aquí se presenta una de las muchas visiones periféricas sobre el derecho que existen en nuestro medio. Considero que hacerlo es ya un avance en la búsqueda de una filosofía para el mundo latino, que reproduciendo esquemas de exclusión que son sufridos a la vez que causados dentro de él, se encuentra imbuido por visiones tradicionales sobre el derecho, los derechos, el estado y la sociedad. No obstante, resulta claro que plantear estos elementos mínimos no puede ser considerado como un éxito. Aún dentro de estas páginas, no es posible encontrar, si no es que tangencialmente, a aquellos a los que se les

\footnotetext{
66- Un modelo de acumulación no es solamente una forma de producción material sino también, una forma específica de reproducción simbólica. Para comprender este concepto resulta importante hablar de aquello que lo compone: el régimen de acumulación describe la estabilización en un largo periodo de la asignación del producto neto entre el consumo y la acumulación: implica cierta correspondencia entre la transformación de las condiciones de producción y las condiciones de reproducción de los asalariados. Esto implica necesariamente que debe introducirse una cierta forma de comportamientos de todo tipo de individuos en una configuración que mantenga funcionando dicho régimen de acumulación, es decir una forma concreta de materialización que tome la forma de normas, hábitos, leyes, redes de regulación y que aseguren la unidad del proceso, es decir la conveniente consistencia de los comportamientos individuales respecto del esquema de reproducción. Este cuerpo de reglas y procesos sociales interiorizados se denomina el modo de regulación. A la unión de un régimen de acumulación específico con su correspondiente modo de regulación, se le conoce como modelo de acumulación. Harvey, David, La condición de la posmodernidad, Madrid, Amorrortu, 2000, cap. 7.
}

67- Como dijera Marx, libre en un doble sentido; se ha liberado de los yugos de su pasado feudal y ha sido forzado a liberarse también de los medios de su propia subsistencia. Marx, Carlos, El capital. Crítica de la economía política, tomo I, México, Fondo de Cultura, 2008, p.122

68- Un estudio pormenorizado de esto lo podemos encontrar en el magnífico trabajo de Tigar, Michell E y Madelaine Levy, El derecho y el ascenso del Capitalismo, México, Siglo XXI, 1986.

69- Foucault, Michel, Vigilar y castigar. El nacimiento de la prisión, México, Siglo XXI, 2008.

70- Foucault, Michel, Historia de la sexualidad, tomo 1: La voluntad de saber, México, Siglo XXI, 2009.

71- Es fácil encontrar similitudes entre esta pugna y la llevada a cabo siglos antes por el cambio de paradigma que significó la disputa entre el ius y la lex. Al respecto, Schiavone, lus... óp. cit. Segunda parte: Cómo nace una técnica. 
niega la voz que poseen, quienes están más allá de la línea abisal que divide el mundo entre "los que saben", "los que no saben" y "los que ni siquiera pueden llegar a saber".

Por ello, considero que el presente trabajo se encuentra aún incompleto; en él he establecido los parámetros que considero, son básicos para una mutua comprensión entre las visiones tradicionales y el trabajo que desarrollamos desde la CJL. Este rodeo, que resulta necesario debido a las relaciones desiguales norte- sur, es tan sólo el primer paso. Después de todo, la preocupación principal de la Crítica Jurídica Latinoamericana es lograr un mundo más justo para todas y todos; ${ }^{72}$ por lo que se encuentra obligada a una búsqueda constante de justicia cognitiva ${ }^{73}$ al mismo tiempo que se esfuerza por la mejora material de la vida cotidiana de la gente.

Para hacer esto, la CJL usará, aunque no de forma exclusiva tanto la práctica como el estudio sistemático del derecho. Pero este no puede ser visto, de acuerdo a lo que aquí hemos establecido, como algo neutro, ahistórico, natural o necesario. Se trata de un sistema normativo específico, social y temporalmente delimitado que requiere para existir, de muchas condiciones igualmente contingentes, ${ }^{74}$ las cuales cobran sentido a través de la existencia de ciertos marcos epistémicos que limitan sus posibilidades.

A pesar de ello, debemos recordar que las formas sociales no se encuentran tan sólo establecidas, sino que se restablecen y reelaboran a través y mediante la lucha y la contradicción. ${ }^{75}$ Por eso es posible su transformación y es ahí donde se encuentra su potencialidad; aun cuando se encuentre fundado en la explotación y el antagonismo, el derecho es, por ello mismo, es al mismo tiempo, terreno de la resistencia y la rebelión.

\section{Mesografía.}

Beuchot, Mauricio, Tratado de hermenéutica analógica, México, Universidad Nacional Autónoma de México, 2009.

Bonefeld, Werner et al., Marxismo abierto, una visión europea y latinoamericana, Vol. II, Buenos Aires, Herramienta, 2007.

Bourdieu, Pierre, "La fuerza del derecho. Elementos para una sociología del campo jurídico", Poder, derecho y clases sociales, Bilbao, Desclée de Brouwer, 2000.

Bourdieu, Pierre, La fuerza del Derecho, Bogotá, Siglo del hombre editores, Facultad de Derecho Universidad de los Andes, Ediciones UniAndes, Instituto Pensar, 2000.

Bourdieu, Pierre y Jean Claude Passeron, Los herederos, México, Siglo XXI, 1998. Bourdieu, Pierre et al., El oficio de sociólogo, México, Siglo XXI, 2008.

Correas, Oscar, "Acerca de la crítica jurídica" en El otro derecho, número 5, marzo de 1990, ILSA, Bogotá D.C., Colombia, pp. 35- 51.

Correas, Oscar, "Conferencia Inaugural” en VIII Conferencia Latinoamericana de Crítica Jurídica

72- Correas, Oscar, "Los derechos humanos. Entre la historia y el mito II", Crítica jurídica, Crítica Jurídica, Revista latinoamericana de política, filosofía y derecho, Número 26, 2007, México, Universidad Nacional Autónoma de México, Universidad de Buenos Aires, Complexo de Ensino Superior do Brasil- Faculdades do Brasil, Fundación Iberoamericana de Derechos Humanos, p. 33.

73- Santos, Boaventura de Sousa, El milenio huérfano. Ensayos para una nueva cultura política, Trotta/ILSA, Madrid, 2005, p. 185.

74- Aunque con reservas, esta aseveración sigue el planteamiento de Pashukanis, Eugeny B., Teoría general del derecho y el marxismo, óp. cit., pp. 70 y ss.

75- Holloway, John, “El estado y la lucha cotidiana” óp. cit., p. 23. 
Jornada Argentina, Universidad Nacional de La Plata, La Plata, 29- 30 de agosto de 2013.

Correas, Oscar, Derecho indígena mexicano, tomo 1, México, Coyoacán, 2011.

Correas, Oscar, "El derecho como forma social" en Ideología jurídica, Puebla, Universidad Autónoma de Puebla, 1983.

Correas, Oscar, "La teoría general del derecho frente a los procesos de integración" en Witker, Jorge (coord.), El tratado de libre comercio de América del Norte, Tomo II, México, Universidad Nacional Autónoma de México, 1993.

Correas, Oscar, "Los derechos humanos. Entre la historia y el mito II", Crítica jurídica, Crítica Jurídica, Revista latinoamericana de política, filosofía y derecho, Número 26, 2007, México, Universidad Nacional Autónoma de México, Universidad de Buenos Aires, Complexo de Ensino Superior do Brasil- Faculdades do Brasil, Fundación Iberoamericana de Derechos Humanos.

Dworkin, Ronald, El imperio de la justicia, De la teoría general del derecho, de las decisiones e interpretaciones de los jueces y de la integridad política y legal como clave de la teoría y práctica, Barcelona, Gedisa, 1992.

Fitzpatrick, Peter, La mitología del derecho moderno, México, Siglo XXI, 1998. Foucault, Michel, La arqueología del saber, México, Siglo XXI, 2007.

Foucault, Michel, Genealogía del racismo, La Plata, Caronte, 1996.

Foucault, Michel, Historia de la sexualidad, tomo 1: La voluntad de saber, México, Siglo XXI, 2009. Foucault, Michel, "Poderes y Estrategias", Un diálogo sobre el poder y otras conversaciones, Madrid, Alianza, 2008.

Foucault, Michel, Vigilar y castigar. El nacimiento de la prisión, México, Siglo XXI, 2008.

Grossi, Paolo, "iJusticia como ley o ley como justicia? Anotaciones de un historiador del derecho" en Mitología jurídica de la modernidad, Madrid, Trotta, 2003.

Habermas, Jürgen, Teoría de la acción comunicativa, Tomo 1: Racionalización de la acción y racionalización social, Madrid, Taurus, 1999.

Harvey, David, La condición de la posmodernidad, Madrid, Amorrortu, 2000.

Holloway, John, "El estado y la lucha cotidiana" en Cuadernos políticos, número 24, México, Distrito Federal, editorial Era, abril-junio 1980.

Horkheimer, Max, Estado autoritario, trad. Bolívar Echeverría, México, Ítaca, 2006.

Horkheimer, Max, La racionalidad instrumental, Madrid, Trotta, 2006.

Horkheimer, Max, "Teoría tradicional y teoría critica” en Teoría crítica, Buenos Aires, Amorrortu, 2008. Jeammaud, Antoine, Sur critique de droit, conferencia impartida en el evento "Franco- American Legal Influences, Then and Now" celebrado el 12 y 13 de junio de 2011 en la Harvard Law School. Kelsen, Hans, Teoría comunista del derecho y el estado, Buenos Aires, Emecé, 1957.

Kelsen, Hans, Teoría general del derecho y del estado, México, Universidad Nacional Autónoma de México, 2010.

Kelsen, Hans, Teoría pura del derecho, México, Porrúa, 2008.

Marx, Karl, "Cartas de Marx a Ruge (marzo y septiembre de 1843)", Escritos de Juventud sobre el Derecho, Textos 1837-1847, Rubén Jaramillo (trad., y ed.), Barcelona, Anthropos, 2008.

Marx, Karl, El capital. Crítica de la economía política, tomo I, México, Fondo de Cultura, 2008.

Marx, Karl, El capital, crítica de la economía política, Tomo III, México, Fondo de Cultura Económica, 2008.

Marx, Karl, "Tesis sobre Feuerbach", desde: https://www.marxists.org/espanol/m-e/1840s/45feuer.htm, consultado el 23 de abril de 2016.

Miaille, Michel, "La especificidad de la forma jurídica burguesa" en La crítica jurídica en Francia, Puebla, Universidad Autónoma de Puebla, 1986.

Pashukanis, E., Teoría general del derecho y el marxismo, México, Grijalbo, 1976. Pérez Lledó, 
Juan, El movimiento de los critical legal studies, Madrid, Tecnos, 1996.

Pina Vara, Rafael de, "Aforismos y frases latinas" en Diccionario de derecho, México, Porrúa, 1997. Poulantzas, Nicos, "La teoría marxista del estado", Hegemonía y dominación en el estado moderno", Buenos Aires, Siglo XXI, 1969, Cuadernos de pasado y Presente 48.

Salazar Bondy, Augusto, ¿Existe una filosofía de Nuestra América?, México, Siglo XXI, 2008.

Santos, Boaventura de Sousa, "Beyond abyssal thinking. From Global Lines to Ecology of Knowledges" desde: http://www.boaventuradesousasantos.pt/media/pdfs/Beyond_Abyssal_Thinking_Review_2007.PDF, consultado el 23 de abril de 2016.

Santos, Boaventura de Sousa, Crítica a la razón indolente, Bilbao, Descleé de Brouwer, 2000.

Santos, Boaventura de Sousa, Decolonizar el poder, reinventar el poder, Montevideo, Trilce, 2010. Santos, Boaventura de Sousa, “¿É possível decolonizar o marxismo? Capitalismo, colonialismo e patriarcado", Segunda aula magistral 2016, desde: https://www.youtube.com/watch?v=79rUpxLI_NI, consultado el 23 de abril de 2016.

Santos, Boaventura de Sousa, El milenio huérfano. Ensayos para una nueva cultura política, Trotta/ILSA, Madrid, 2005.

Santos, Boaventura de Sousa, "La sociología de las ausencias y la sociología de las emergencias: para una ecología de saberes", Renovar la teoría crítica y reinventar la emancipación social (encuentros en Buenos Aires), Buenos Aires, agosto 2006.

Schiavone, Aldo, lus. La invención del derecho en occidente, Buenos Aires, Adriana Hidalgo editora, 2009. Stucka, P. I., La función revolucionaria del derecho y el estado, Barcelona, Península, 1969.

Tamayo y Salmorán, Rolando, Introducción analítica al estudio del derecho, México, Themis, 2011. Tamayo y Salmorán, Rolando, Razonamiento y argumentación jurídica. El paradigma de la racionalidad y la ciencia del derecho, México, Universidad Nacional Autónoma de México, Instituto de Investigaciones Jurídicas, 2003.

Tigar, Michell E y Madelaine Levy, El derecho y el ascenso del Capitalismo, México, Siglo XXI, 1986. Weber, Max, Economía y sociedad, México, esbozo de sociología comprensiva, Fondo de Cultura Económica, 2008.

Weber, Max, "Introducción”, Ensayos sobre sociología de la religión, tomo 1, Madrid, Taurus, 1987. Weber, Max, La ética protestante y el espíritu del capitalismo, México, Colofón, 2004.

Wolkmer, Antonio Carlos, Introducción al pensamiento jurídico crítico, Bogotá, Instituto Latinoamericano de Servicios Legales Alternativos, 2003.

Zea, Leopoldo, La filosofía americana como filosofía sin más, México, Siglo XXI, 2011. 